\title{
Stand-Alone Cages for Anterior Cervical Fusion: Are There No Problems?
}

\author{
Sang Youp Han ${ }^{1}$, Hyun Woo Kim¹, Cheol Young Lee ${ }^{1}$, Hong Rye Kim¹, Dong Ho Park ${ }^{2}$ \\ Departments of ${ }^{I}$ Neurosurgery and ${ }^{2}$ Anesthesiology, Konyang University Hospital, \\ Konyang University Collge of Medicine, Daejon, Korea
}

Objective: There are complications in stand-alone cage assisted anterior cervical discectomy and fusion (ACDF), such as cage subsidence and kyphosis. Here we report our clinical result on ACDF, comparing with stand-alone cages and with cervical plate system for degenerative cervical spine diseases.

Methods: Patients with degenerative cervical disease who were diagnosed and treated in Konyang University Hospital between January 2004 and December 2014 were included in this study. Patients who had operation in single level ACDF were selected. Patients scored the degree of pain using visual analog scale before and after the surgery. Subsidence was defined as $\geq 3-\mathrm{mm}$ decrease of the segmental height, and cervical kyphosis was defined as progression of $\geq 5^{\circ}$ at 12 months after postoperative follow-up compared to that measured at the immediate postoperative period.

Results: A total of 81 patients were enrolled for this study. Forty-five patients were included in a cervical plate group and the others were in stand-alone cage group. There was no statistical difference in pain score between the 2 groups. Segmental subsidence was observed in 7 patients (15.6\%) in plate-assisted cervical fusion group, and 13 patients (36.1\%) in stand-alone cage group. Segmental kyphosis was observed in 4 patients (8.9\%) in plate-assisted cervical fusion group, and 10 patients (27.8\%) in stand-alone cage group. There was statistical difference between the 2 groups.

Conclusion: There was no difference in pain between 2 groups. But stand-alone case group showed higher incidence rate than plate-assisted cervical fusion group in segmental subsidence and cervical kyphosis. When designing cervical fusion, more attention should be given selecting the surgical technique.

Key Words: Stand-alone cervical fusion $\cdot$ Segmental subsidence $\cdot$ Cervical kyphosis $\cdot$ Plate-assisted cervical fusion

\section{INTRODUCTION}

Anterior cervical discectomy and fusion (ACDF) is the most frequently performed surgical treatment for several cervical spinal diseases, including herniated disc, compressive myelopathy, trauma and degenerative disease ${ }^{8,15)}$. This procedure is used to decompress the spinal cord and nerve root, and to stabilize the affected segments ${ }^{7,25)}$.

Smith and Robinson ${ }^{36)}$ 's technique had been the "gold standard" for the surgical treatment of cervical disc disease. However, anterior cervical plates with iliac bone grafts lead to chronic iliac pain ${ }^{16,35)}$ and higher rates of dysphagia ${ }^{11,12,22,31,37)}$. For those reasons, several technical modifications of this procedure have been developed such as stand-alone cages, anterior

- Received: December 26, 2015 • Revised: February 4, 2016

- Accepted: February 5, 2016

Corresponding Author: Hyun Woo Kim, MD, PhD

Department of Neurosurgery, Konyang University Hospital, 158

Gwanjeodong-ro, Seo-gu, Daejeon 35365, Korea

Tel: +82-42-600-9130, Fax: +82-42-600-8983

E-mail: naturalspine@gmail.com

$\otimes$ This is an open access article distributed under the terms of the Creative Commons Attribution Non-Commercial License (http://creativecommons.org/licenses/by-nc/4.0/) which permits unrestricted non-commercial use, distribution, and reproduction in any medium, provided the original work is properly cited. cervical plates, zero-profile devices etc. But there is currently no consensus regarding the optimal technique ${ }^{18)}$.

Among these procedures, cervical intervertebral disc replacement by a stand-alone cage provides immediate load bearing support to the anterior column and may facilitate arthrodesis. On the other hand, there is evidence documenting relatively frequent complications in stand-alone cage assisted ACDF, such as cage subsidence and cervical kyphosis ${ }^{9}$.

In this situation, plate-assisted cervical fusion is good alternations to stand-alone cervical fusion. But, there are only a few direct comparative researches in clinical and radiological outcomes between the 2 groups.

Here we report our clinical result of ACDF over 10 years, comparing interbody fusion with stand-alone cage and plateassisted cervical fusion for degenerative cervical spine diseases.

\section{MATERIALS AND METHODS}

This study was retrospective study on patients with degenerative cervical disease diagnosed and treated in Konyang University Hospital between January 2004 and December 2014. We evaluated total 81 patients treated with a single level ACDF. The surgery was performed by 3 neurosurgeons in a Konyang University Hospital. But, most of surgery was performed by 1 surgeon (sur- geon A, 75 cases; surgeon B, 4 cases; 
surgeon C, 2 cases). Patients were kept in a soft collar for 8-12 weeks after surgery. And they were treated similar postoperative care such as antibiotics and pain killers etc.

They were divided into 2 groups; plate-assisted cervical fusion in group $A(n=45)$ and stand-alone cages in group $B(n=36)$. And follow-up duration for both groups was 12 months. The patients were randomly selected for each surgical methods.

Inclusion criteria were; (1) signs and symptoms of cervical radiculopathy or cervical spondylotic myelopathy which was unresponsive to the medical treatment, (2) single level disease confirmed by clinical symptom and imaging (plain X-ray and magnetic resonance imaging $[\mathrm{MR}])$, and (3) continuous clinical follow-up and imaging data over 1 year.

The exclusion criteria were; (1) history of previous cervical spine surgery, (2) others cervical disease, including infection, tumor, deformity etc., and (3) requirement for multilevel fusion or simultaneous anterior and posterior surgery.

\section{Demographic Data}

Patients' demographic data were collected on chart and plain X-ray, MRI. The preoperative study included plain radiographs and MRI of cervical spine. Patients' demographic data included age, sex, affected cervical level, and types of symptom etc.

\section{Pain Results}

Patients' pains were evaluated using visual analog scale (VAS) for neck pain and radicular pain before and after the surgery. Preoperative pain was checked in admission time. And regular follow-up was done immediately after surgery, 3 months, 6 months, and 12 months.

\section{Surgical Technique}

The surgical site was exposed via a standard anterior ap-
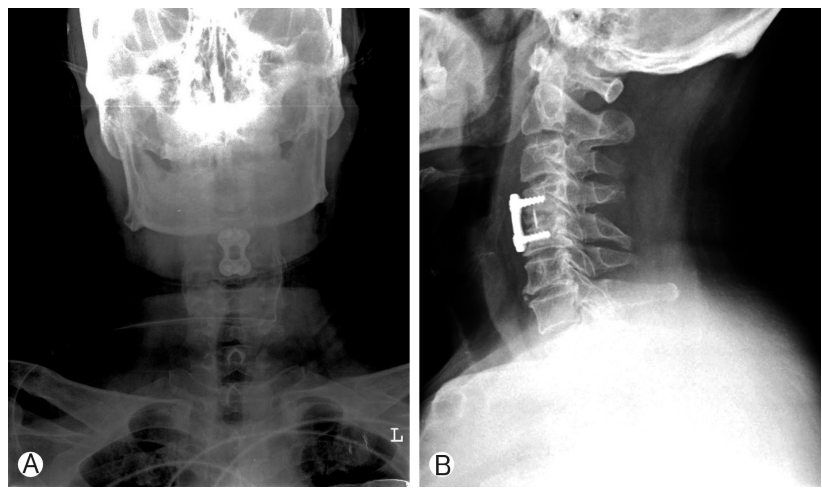

Fig. 1. Postoperative radiographs showing the anterior cervical plate with autologous bone graft for a single level cervical disease. (A) Posterior anterior view. (B) Lateral view. proach $^{36)}$ and microscopic anterior cervical discectomy was performed. After neural decompression was performed, the interbody fusion was performed using a PEEK cage (Solis, Stryker Spine, Allendale, NJ, USA). And plate-assisted cervical fusion group was accomplished with anterior cervical plates fixed by 4 screws (Figs. 1, 2). Plate was randomly selected, but mainly used Atlantis plate (Medtronic Sofamor-Danek, Memphis, TN, USA). The demineralized bone matrix was filled into the cage for fusion in groups $\mathrm{A}$ and $\mathrm{B}$.

\section{Radiological Evaluation}

Anteroposterior and lateral plain radiographs were obtained before and immediately after the surgery and 12 months later. MRI scans were also obtained before surgery.

The construct length and spinal curvature were measured to compare stand-alone cage group and plate-assisted cervical fusion group. The construct length was measured as the distance from the midpoint between the anterior and posterior aspects of the superior endplate of the top level of the fusion to the midpoint of the inferior endplate of the bottom level of the fusion on the plain radiographs (Fig. 3).

Subsidence was defined as $3 \mathrm{~mm}$ or more decrease of the
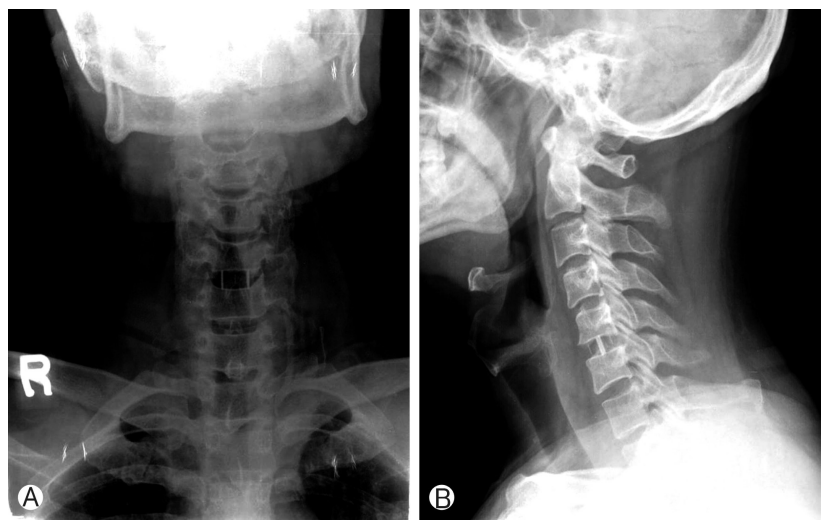

Fig. 2. Postoperative radiographs showing the stand-alone cage for a single level cervical disease. (A) Posterior anterior view. (B) Lateral view.

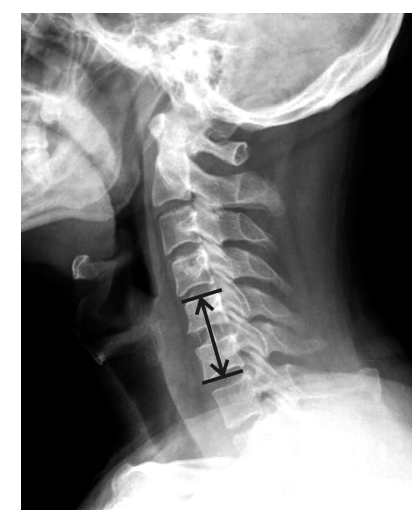

Fig. 3. The construct length was measured as the distance between the middle margin of the upper end plate of the upper vertebra and the middle margin of the lower end plate of the lower vertebra. 
segmental height at the postoperation 1 year follow-up compared to that measured at the immediate postoperative period ${ }^{3}$.

Cervical spinal curvature was measured by the method of Cobb angle. The Cobb angle is defined as the angle formed between a line drawn parallel to the superior endplate of one vertebra above the herniated disc and a line drawn parallel to the inferior endplate of the vertebra one level below herniated disc (Fig. 4).

Cervical kyphosis was defined as progression of $\geq 5^{\circ}$ at the postoperative 12-month follow-up compared to that measured at the immediate postoperative period ${ }^{23)}$.

\section{Statistical Analysis}

The statistical analysis was performed using SPSS ver. 13.0 (SPSS Inc., Chicago, IL, USA). Statistical comparison was made between stand-alone cage group and plate-assisted cervical fusion group based on the pain results and radiologic data. The baseline variables included the age, VAS score, segmental subsidence and cervical kyphosis. These variables were compared using the chi- square test and independent sample t-test. A $\mathrm{p}$-value of 0.05 was considered as significant.

\section{RESULTS}

\section{Demographic Data}

There was no demographic difference between the 2 groups. The mean age of 81 patients was 58.3 years (range, 34-86 years). Fifty-four patients were male, 27 patients were female. Most common operation site was C5-6 (40.7\%). C6-7 (29.6\%) was second common operation site (Fig. 5). Fifty-eight patients $(71.6 \%)$ had radiculopathy, and 23 patients (28.4\%) had myelopathy symptoms (Table 1 ).

\section{Surgical Data}

The surgery was predominantly performed by 1 surgeon

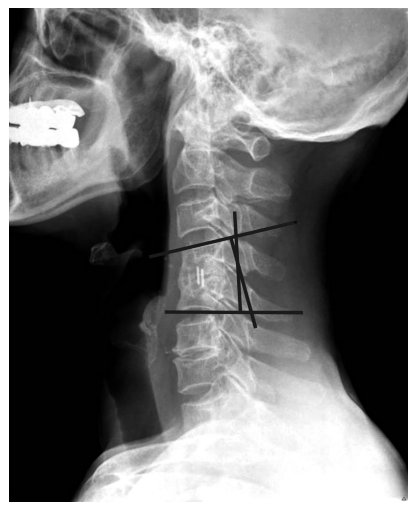

Fig. 4. Segmental lordosis was measured using Cobb method. (surgeon A, 75 cases; surgeon B, 4 cases; surgeon C, 2 cases). The operation methods were randomly selected. Stand-alone cage group inserted a PEEK cage (Solis) in 36 patients (100\%). And plate-assisted cervical fusion group also inserted a PEEK cage, but the plate is different. Twenty-one patients (46.7\%) used Atlantis plate, 11 patients (24.4\%) used $\mathrm{ABC}$ plate, 9 patients (20.0\%) used Vectra plate, and 4 patients (8.9\%) used Maxima plate (Table 2).

\section{Pain Score}

The patients clinical symptom, especially pain showed no statistically difference in preoperative, immediate postoperative, 3-month, 6-month, and 12-month follow-up between the 2 groups (Table 3). Pain score during 12 months has improved

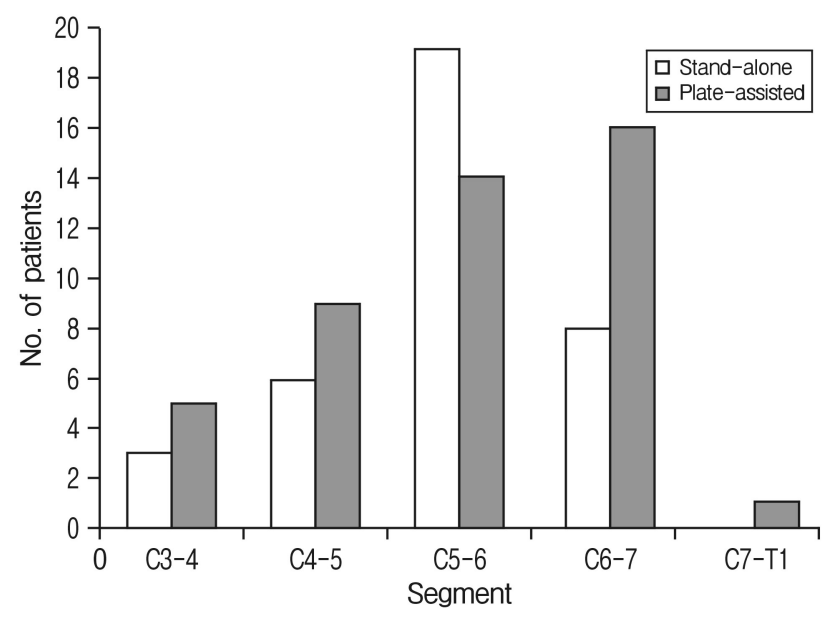

Fig. 5. Operation site for cervical degenerative disease.

Table 1. Demographic data of the 2 groups

\begin{tabular}{lcc}
\hline \hline Demographic & $\begin{array}{c}\text { Plate-assisted cervical } \\
\text { fusion group }(\mathrm{n}=45)\end{array}$ & $\begin{array}{c}\text { Stand-alone cage } \\
\text { group }(\mathrm{n}=36)\end{array}$ \\
\hline Age (yr) & $56.70 \pm 9.9$ & $60.16 \pm 10.99$ \\
Sex & & \\
$\quad$ Male & $30(66.7)$ & $24(66.7)$ \\
$\quad$ Female & $15(33.3)$ & $12(33.3)$ \\
Affected segment & & \\
C3-4 & $5(11.1)$ & $3(8.3)$ \\
C4-5 & $9(20.0)$ & $6(16.7)$ \\
C5-6 & $14(31.1)$ & $19(52.8)$ \\
C6-7 & $16(35.6)$ & $8(22.2)$ \\
C7-T1 & $1(2.2)$ & \\
Type of symptom & & \\
Radiculopathy & $32(71.1)$ & $26(72.2)$ \\
Myelopathy & $13(28.9)$ & $10(27.8)$ \\
\hline
\end{tabular}

Values are presented as mean \pm standard deviation or number (\%). 
Table 2. Surgical data of the 2 groups

\begin{tabular}{lcc}
\hline \hline Variable & $\begin{array}{c}\text { Plate-assisted } \\
\text { cervical fusion } \\
\text { group }(\mathrm{n}=45)\end{array}$ & $\begin{array}{c}\text { Stand-alone } \\
\text { cage group } \\
(\mathrm{n}=36)\end{array}$ \\
\hline $\begin{array}{c}\text { Type of instrumentation } \\
\text { PEEK cage alone }\end{array}$ & - & $36(100)$ \\
ABC plate & $11(24.4)$ & - \\
Atlantis plate & $21(46.7)$ & - \\
Vectra plate & $9(20.0)$ & - \\
Maxima plate & $4(8.9)$ & - \\
Surgeon & & \\
A & $42(93.3)$ & $33(91.7)$ \\
B & $3(6.7)$ & $1(2.8)$ \\
C & $0(0)$ & $2(5.6)$ \\
\hline
\end{tabular}

Values are presented as number (\%).

Table 3. Pain results of the 2 groups

\begin{tabular}{lccc}
\hline \hline Variable & $\begin{array}{c}\text { Plate-assisted } \\
\text { cervical fusion } \\
\text { group }(\mathrm{n}=45)\end{array}$ & $\begin{array}{c}\text { Stand-alone } \\
\text { cage group } \\
(\mathrm{n}=36)\end{array}$ & p-value \\
\hline Preoperative & $7.58 \pm 1.06$ & $7.69 \pm 0.92$ & 0.602 \\
Postoperative & $4.91 \pm 1.50$ & $4.81 \pm 1.58$ & 0.760 \\
3 Months & $3.78 \pm 1.33$ & $3.86 \pm 1.51$ & 0.793 \\
6 Months & $3.47 \pm 1.42$ & $3.08 \pm 1.18$ & 0.198 \\
12 Months & $3.33 \pm 1.37$ & $2.94 \pm 1.31$ & 0.198 \\
VAS improvement & $4.75 \pm 1.98$ & $4.24 \pm 1.61$ & 0.208 \\
\hline
\end{tabular}

Values are presented as mean \pm standard deviation.

VAS, visual analog scale.

in both groups. And mean preoperative pain score was $7.58 \pm$ 1.06 vs. $7.69 \pm 0.92$ and 12 -month follow-up pain score was $3.33 \pm 1.37$ vs. $2.94 \pm 1.31$. The mean pain improvement was $4.75 \pm 1.98$ vs. $4.24 \pm 1.61$. There was no significant difference between 2 groups $(p=0.208)$.

\section{Segmental Subsidence}

Thirteen out of 36 patients (36.1\%) were found the segmental subsidence in stand-alone cage group. Mean segmental subsidence was $4.28 \pm 2.45 \mathrm{~mm}$ during 12-month follow-up. But only 7 out of 45 patients $(15.6 \%)$ were founded the segmental subsidence in plate-assisted cervical fusion group. Mean segmental subsidence was $4.57 \pm 3.33 \mathrm{~mm}$. Subsidence occurrence rate was statistically different between the 2 groups $(p=0.033)$ (Table 4).

\section{Segmental Cervical Kyphosis}

Segmental cervical kyphosis was also different between the
Table 4. Comparison of the radiologic results between the plate-assisted cervical fusion group and stand-alone cage group

\begin{tabular}{lccc}
\hline \hline Variable & $\begin{array}{c}\text { Plate-assisted } \\
\text { cervical fusion } \\
\text { group }(\mathrm{n}=45)\end{array}$ & $\begin{array}{c}\text { Stand-alone } \\
\text { cage group } \\
(\mathrm{n}=36)\end{array}$ & p-value \\
\hline Construct height & & & \\
$\quad$ Preoperative $(\mathrm{mm})$ & $38.77 \pm 4.66$ & $38.13 \pm 3.52$ & 0.501 \\
Postoperative $(\mathrm{mm})$ & $34.20 \pm 3.0$ & $33.85 \pm 2.94$ & 0.607 \\
Segmental subsidence & $4.57 \pm 3.33$ & $4.28 \pm 2.45$ & 0.663 \\
No. of subsidence & $7(15.6)$ & $13(36.1)$ & 0.033 \\
Cervical kyphosis & & & \\
Preoperative $\left({ }^{\circ}\right)$ & $4.95 \pm 4.25$ & $5.78 \pm 3.77$ & 0.362 \\
Postoperative $\left({ }^{\circ}\right)$ & $5.74 \pm 3.77$ & $3.88 \pm 3.52$ & 0.025 \\
Kyphotic change $\left(^{\circ}\right)$ & $0.03 \pm 3.56$ & $1.08 \pm 5.54$ & 0.304 \\
No. of kyphosis & $4(8.9)$ & $10(27.8)$ & 0.025 \\
\hline
\end{tabular}

Values are presented as mean \pm standard deviation or number (\%).

2 groups. Ten out of 36 patients (27.8\%) were showed cervical kyphosis on stand-alone cage group. On the other hand, 4 out of 45 patients (8.9\%) showed cervical kyphosis on plateassisted cervical fusion group. Mean cervical kyphotic change is $1.08^{\circ} \pm 5.54^{\circ}$ vs. $0.03^{\circ} \pm 3.56^{\circ}$. Between the 2 groups, segmental cervical kyphosis occurrence rate was statistically different $(p=0.025)$ (Table 4).

\section{DISCUSSION}

ACDF is widely accepted surgical procedure for the treatment of cervical spinal degenerative disease ${ }^{6,10,26,29)}$. However, the classic method of Cloward ${ }^{9}$ and Smith and Robinson ${ }^{36}$ using an autologous tricortical iliac bone graft has been reported to have problems of donor site morbidity ${ }^{1,35)}$ and subsidence $^{34,40)}$. In order to overcome those problems, ACDF using an intervertebral cage has been recently used with favorable results ${ }^{42)}$.

Stand-alone intervertebral cages can be effective for restoring the intervertebral disc height and lordosis, providing loadbearing support to the anterior column and preventing graft collapse $^{21,23)}$. But nowadays stand-alone cage also reported problems. For example, nonunion and subsidence into the endplates have been reported as the complications of these procedures $^{5,14,23,27,32,39)}$. And some surgeons advocated that plateassisted cervical fusion shows better outcomes than stand-alone cages. So, we designed retrospective study to compare clinical and radiologic outcomes between 2 groups.

Many authors reported that the clinical outcomes between the stand-alone cages and the anterior cervical plates for cervical degenerative disease were similar ${ }^{13,19,20,32)}$. Our study also showed no statistically different between 2 groups on pain score improvement. But, short-term follow-up and short segment surgery can affect this result. 
Table 5. Summary of the studies on stand-alone cage grafts subsidence

\begin{tabular}{lllc}
\hline \hline Study & \multicolumn{1}{c}{ Stand-alone cage } & \multicolumn{1}{c}{ Subsidence } & Percentage \\
\hline Gercek et al. $(2003)^{14)}$ & Titanium & Disc space height $/ \geq 3 \mathrm{~mm}$ & 56 \\
van Jonbergen et al. $(2005)^{39)}$ & Titanium & Segmental height $/ \geq 3 \mathrm{~mm}$ & 9 \\
Schmieder et al. $(2006)^{32)}$ & Titanium & Disc space height $/ \geq 3 \mathrm{~mm}$ & 45 \\
Bartels et al. $(2006)^{5)}$ & Carbon fiber & Disc space height $/ \geq 2 \mathrm{~mm}$ & 29.2 \\
Barsa and Suchomel (2007) ${ }^{2)}$ & Titanium & Segmental height $/ \geq 3 \mathrm{~mm}$ & 13.2 \\
Ha et al. $(2008)^{17)}$ & PEEK & Segmental height $/ \geq 3 \mathrm{~mm}$ & 8.1 \\
Kast et al. $(2009)^{23)}$ & PEEK & Segmental height $/ \geq 2 \mathrm{~mm}$ & 29 \\
Lee et al. $(2009)^{28)}$ & PEEK & Disc space height $\&$ segmental height $/ \geq 2 \mathrm{~mm}$ \\
Shin et al. $(2014)^{33)}$ & PEEK & Segmental height $/ \geq 3 \mathrm{~mm}$ & 44.7 \\
Bartels et al. $(2010)^{3)}$ & Cervical interbody fusion cages & Nonspecific \\
This study $(2015)$ & PEEK & Segmental height $/ \geq 3 \mathrm{~mm}$ & 14 \\
\hline
\end{tabular}

PEEK cage (Solis, Stryker Spine, Allendale, NJ, USA).

Table 6. Summary of the studies on plate-assisted allograft subsidence

\begin{tabular}{lllc}
\hline \hline Study & \multicolumn{1}{c}{ Plate } & \multicolumn{1}{c}{ Subsidence } & Percentage \\
\hline Tye et al. $(2002)^{38)}$ & Atlantis & 6-Week f/u & Mean, $1.11 \mathrm{~mm}$ \\
Kim and Kim (2014) ${ }^{25)}$ & Atlantis & 12-Month f/u/segmental height $/ \geq 3 \mathrm{~mm}$ & $18 \%$ \\
Shin et al. (2014) & Titanium plate & Last f/u (12-15 months)/segmental height $/ \geq 3 \mathrm{~mm}$ & $45 \%$ \\
This study (2015) & Atlantis etc. & 12-Month f/u/segmental height $\geq 3 \mathrm{~mm}$ & $15.3 \%$ \\
\hline
\end{tabular}

f/u, follow-up.

There are some studies compared to stand-alone cages and cervical plating system radiologic outcomes. Bartels et al. ${ }^{5)}$ reported 29.2\% subsidence rate in stand-alone cage group for 6-week follow-up. And Yang et al. ${ }^{42)}$ reported over 3-mm cage subsidence have occurred $14.9 \%$ rate $(n=51)$. Our stand-alone cage group subsidence rate is $36.1 \%$. This rate is similar to previous studies (Table 5). In addition, Kim et al. ${ }^{25)}$ reported subsidence rate of $18 \%$ in plate-assisted cervical fusion at postoperative 1-year follow-up $(n=48)$. Our plate-assisted cervical fusion group subsidence rate is $15.6 \%$ (Table 6). These results are also similar to the other studies. As a result, plate-assisted cervical fusion group's segmental subsidence rate is lower than stand-alone cage group.

Even though many studies reported subsidence does not always result in poor prognosis or aggravation of symptoms and mostly does not cause symptoms or morbidity ${ }^{32,42,43)}$, intervertebral disc height loss can eventually result in narrowing of the foramen, nerve root compression, pseudoarthrosis due to cervical instability ${ }^{4,17)}$. It means that segmental subsidence arouses significant morbidity on postoperative period.

Similar tendency was also observed on cervical lordosis. It shows also this kind of tendency. Barsa and Suchomel ${ }^{2)}$ have studied stand-alone cage group cervical angulation after 6month postoperative follow-up. They reported that using Cobb angle resulted about $8.7^{\circ}$ loss of segmental lordosis. Also Yang et al. $^{42)}$ have studied average $1.58^{\circ}$ cervical angulation change from immediate postoperative to last follow-up stand-alone cage group. And $29.8 \%$ of them changed over $3^{\circ}$. Our studies show that cervical kyphosis was resulted $15.8 \%$ in stand-alone cage group and $7.6 \%$ plate-assisted cervical fusion group. This result indicates not only segmental subsidence but also cervical kyphosis occurrence rate is much higher in stand-alone cage group. Cervical kyphosis can occur disc space narrowing and adjacent segment degeneration ${ }^{24,30)}$.

These results mean that plate-assisted cervical fusion is good alternative of stand-alone cages cervical fusion in degenerative cervical disease. Some studies reported plate-assisted cervical fusion has the drawbacks of high cost, a long operative time, and risk to adjacent structures because of the retraction required for plate insertion ${ }^{41)}$. But the incidence of postoperative complication rate is relatively low and most symptoms were improved as time goes by ${ }^{33)}$.

Plate-assisted cervical fusion group can prevent cage subsidence and cervical kyphosis, even though some author insist radiological results cannot influence clinical outcomes. And there was no statistical difference in pain scores between 2 groups. The results are only limited to short segment and short-term follow-up. We inference long segment fusion resulted more difference than short segment groups. And if time passes, segmental kyphosis affect cervical sagittal imbalance more. Long-term follow-up anticipate pessimistic results.

However, currently we apply only limited plate-assisted cervical fusion because of National Health Insurance does not allow using 2 devices at once. But, this policy can result poor 
outcome and spend more socioeconomic cost of disease.

Unfortunately, this study has some limitations. This is retrospective study showing somewhat selection bias. And we did not consider implanted cage size and cage migration and surgical technique. Barsa and Suchomel ${ }^{2}$ reported they are affected cage subsidence and sagittal imbalance. Another weakness of our study did not consider other clinical symptoms (except pain). And short segment fusion (one level), relatively shortterm follow-up (12 months) were also limitation of this study. But there are little study direct compare to stand-alone cage group and plate-assisted cervical fusion group. Especially, comparison on subsidence and kyphosis at the same time is strong point of our study.

\section{CONCLUSION}

A retrospective review was performed on 81 patients undergoing stand-alone cage group and plate-assisted cervical fusion group. Pain results between 2 groups showed no statistical differences but radiological results showed differences between 2 groups. Stand-alone cage group were much more provoked than plate-assisted cervical fusion group in segmental subsidence and cervical kyphosis. So plate-assisted cervical fusion is good alternative for fusion in patients with cervical degenerative diseases.

\section{CONFLICT OF INTEREST}

No potential conflict of interest relevant to this article was reported.

\section{REFERENCES}

1. Banwart JC, Asher MA, Hassanein RS: Iliac crest bone graft harvest donor site morbidity. A statistical evaluation. Spine (Phila Pa 1976) 20:1055-1060, 1995

2. Barsa P, Suchomel P: Factors affecting sagittal malalignment due to cage subsidence in standalone cage assisted anterior cervical fusion. Eur Spine J 16:1395-1400, 2007

3. Bartels RH, Beems T, Schutte PJ, Verbeek AL: The rationale of postoperative radiographs after cervical anterior discectomy with stand-alone cage for radicular pain. J Neurosurg Spine 12: 275-279, 2010

4. Bartels RH, Donk R, van Azn RD: Height of cervical foramina after anterior discectomy and implantation of a carbon fiber cage. J Neurosurg 95(1 Suppl):40-42, 2001

5. Bartels RH, Donk RD, Feuth T: Subsidence of stand-alone cervical carbon fiber cages. Neurosurgery 58:502-508, 2006

6. Bohlman HH, Emery SE, Goodfellow DB, Jones PK: Robinson anterior cervical discectomy and arthrodesis for cervical radiculopathy. Long-term follow-up of one hundred and twenty-two patients. J Bone Joint Surg Am 75:1298-1307, 1993

7. Botelho RV, Dos Santos Buscariolli Y, de Barros Vasconcelos
Fernandes Serra MV, Bellini MN, Bernardo WM: The choice of the best surgery after single level anterior cervical spine discectomy: a systematic review. Open Orthop J 6:121-128, 2012

8. Cloward RB: The anterior approach for removal of ruptured cervical disks. J Neurosurg 15:602-617, 1958

9. Cloward RB: The anterior approach for removal of ruptured cervical disks. 1958. J Neurosurg Spine 6:496-511, 2007

10. Connolly PJ, Esses SI, Kostuik JP: Anterior cervical fusion: outcome analysis of patients fused with and without anterior cervical plates. J Spinal Disord 9:202-206, 1996

11. Fountas KN, Kapsalaki EZ, Nikolakakos LG, Smisson HF, Johnston KW, Grigorian AA, et al: Anterior cervical discectomy and fusion associated complications. Spine (Phila Pa 1976) 32: 2310-2317, 2007

12. Fowler BL, Dall BE, Rowe DE: Complications associated with harvesting autogenous iliac bone graft. Am J Orthop (Belle Mead NJ) 24:895-903, 1995

13. Fujibayashi S, Neo M, Nakamura T: Stand-alone interbody cage versus anterior cervical plate for treatment of cervical disc herniation: sequential changes in cage subsidence. J Clin Neurosci 15:1017-1022, 2008

14. Gercek E, Arlet V, Delisle J, Marchesi D: Subsidence of standalone cervical cages in anterior interbody fusion: warning. Eur Spine J 12:513-516, 2003

15. Gore DR, Sepic SB: Anterior cervical fusion for degenerated or protruded discs. A review of one hundred forty-six patients. Spine (Phila Pa 1976) 9:667-671, 1984

16. Goulet JA, Senunas LE, DeSilva GL, Greenfield ML: Autogenous iliac crest bone graft. Complications and functional assessment. Clin Orthop Relat Res (339):76-81, 1997

17. Ha SK, Park JY, Kim SH, Lim DJ, Kim SD, Lee SK: Radiologic assessment of subsidence in stand-alone cervical polyetheretherketone (PEEK) cage. J Korean Neurosurg Soc 44:370-374, 2008

18. Hida K, Iwasaki Y, Yano S, Akino M, Seki T: Long-term followup results in patients with cervical disk disease treated by cervical anterior fusion using titanium cage implants. Neurol Med Chir (Tokyo) 48:440-446, 2008

19. Huh J, Oh JY, Chough CK, Cho CB, Joo WI, Park HK: Polyetheretherketone cage filled with beta-tricalcium phosphate versus autogenous tricortical iliac bone graft in anterior cervical discectomy and fusion. Korean J Spine 8:165-171, 2011

20. Joo YH, Lee JW, Kwon KY, Rhee JJ, Lee HK: Comparison of fusion with cage alone and plate instrumentation in two-level cervical degenerative disease. J Korean Neurosurg Soc 48:342346, 2010

21. Kandziora F, Pflugmacher R, Schäfer J, Born C, Duda G, Haas $\mathrm{NP}$, et al: Biomechanical comparison of cervical spine interbody fusion cages. Spine (Phila Pa 1976) 26:1850-1857, 2001

22. Kasimatis GB, Panagiotopoulos E, Gliatis J, Tyllianakis M, Zouboulis P, Lambiris E: Complications of anterior surgery in cervical spine trauma: an overview. Clin Neurol Neurosurg 111: 18-27, 2009

23. Kast E, Derakhshani S, Bothmann M, Oberle J: Subsidence after anterior cervical inter-body fusion. A randomized prospective clinical trial. Neurosurg Rev 32:207-214, 2009

24. Katsuura A, Hukuda S, Saruhashi Y, Mori K: Kyphotic malalignment after anterior cervical fusion is one of the factors pro- 
moting the degenerative process in adjacent intervertebral levels. Eur Spine J 10:320-324, 2001

25. Kim SJ, Kim SD: Anterior cervical discectomy and fusion using a double cylindrical cage versus an anterior cervical plating system with iliac crest autografts for the treatment of cervical degenerative disc disease. J Korean Neurosurg Soc 55:12-17, 2014

26. Kolstad F, Nygaard ØP, Andresen H, Leivseth G: Anterior cervical arthrodesis using a "stand alone" cylindrical titanium cage: prospective analysis of radiographic parameters. Spine (Phila Pa 1976) 35:1545-1550, 2010

27. Kulkarni AG, Hee HT, Wong HK: Solis cage (PEEK) for anterior cervical fusion: preliminary radiological results with emphasis on fusion and subsidence. Spine J 7:205-209, 2007

28. Lee SH, Suk KS, Kim KT, Lee JH, Seo EM, Im YS: Outcome analysis of single level anterior cervical fusion using interbody PEEK cage with autologous iliac bone graft. J Korean Orthop Assoc 44:93-101, 2009

29. Lind BI, Zoega B, Rosén H: Autograft versus interbody fusion cage without plate fixation in the cervical spine: a randomized clinical study using radiostereometry. Eur Spine J 16:1251-1256, 2007

30. Oda I, Cunningham BW, Buckley RA, Goebel MJ, Haggerty CJ, Orbegoso CM, et al: Does spinal kyphotic deformity influence the biomechanical characteristics of the adjacent motion segments? An in vivo animal model. Spine (Phila Pa 1976) 24: 2139-2146, 1999

31. Riley LH Jr, Robinson RA, Johnson KA, Walker AE: The results of anterior interbody fusion of the cervical spine. Review of ninety-three consecutive cases. J Neurosurg 30:127-133, 1969

32. Schmieder K, Wolzik-Grossmann M, Pechlivanis I, Engelhardt M, Scholz M, Harders A: Subsidence of the wing titanium cage after anterior cervical interbody fusion: 2-year follow-up study. J Neurosurg Spine 4:447-453, 2006

33. Shin JS, Oh SH, Cho PG: Surgical outcome of a zero-profile device comparing with stand-alone cage and anterior cervical plate with iliac bone graft in the anterior cervical discectomy and fusion. Korean J Spine 11:169-177, 2014

34. Siddiqui AA, Jackowski A: Cage versus tricortical graft for cervical interbody fusion. A prospective randomised study. J Bone Joint Surg Br 85:1019-1025, 2003

35. Silber JS, Anderson DG, Daffner SD, Brislin BT, Leland JM, Hilibrand AS, et al: Donor site morbidity after anterior iliac crest bone harvest for single-level anterior cervical discectomy and fusion. Spine (Phila Pa 1976) 28:134-139, 2003.

36. Smith GW, Robinson RA: The treatment of certain cervicalspine disorders by anterior removal of the intervertebral disc and interbody fusion. J Bone Joint Surg Am 40-A:607-624, 1958

37. Thorell W, Cooper J, Hellbusch L, Leibrock L: The long-term clinical outcome of patients undergoing anterior cervical discectomy with and without intervertebral bone graft placement. Neurosurgery 43:268-273, 1998

38. Tye GW, Graham RS, Broaddus WC, Young HF: Graft subsidence after instrument-assisted anterior cervical fusion. J Neurosurg 97(2 Suppl):186-192, 2002

39. van Jonbergen HP, Spruit M, Anderson PG, Pavlov PW: Anterior cervical interbody fusion with a titanium box cage: early radiological assessment of fusion and subsidence. Spine J 5:645-649, 2005

40. Vavruch L, Hedlund R, Javid D, Leszniewski W, Shalabi A: A prospective randomized comparison between the cloward procedure and a carbon fiber cage in the cervical spine: a clinical and radiologic study. Spine (Phila Pa 1976) 27:1694-1701, 2002

41. Whitecloud TS 3rd. Modern alternatives and techniques for one-level discectomy and fusion. Clin Orthop Relat Res (359): 67-76, 1999

42. Yang JJ, Yu CH, Chang BS, Yeom JS, Lee JH, Lee CK: Subsidence and nonunion after anterior cervical interbody fusion using a stand-alone polyetheretherketone (PEEK) cage. Clin Orthop Surg 3:16-23, 2011

43. Zdeblick TA, Ducker TB: The use of freeze-dried allograft bone for anterior cervical fusions. Spine (Phila Pa 1976) 16:726-729, 1991 